\title{
Phenazine and 1-Undecene Producing Pseudomonas chlororaphis subsp. aurantiaca Strain KNU17Pc1 for Growth Promotion and Disease Suppression in Korean Maize Cultivars ${ }^{\mathbb{S}}$
}

\author{
Setu Bazie Tagele, Hyun Gu Lee, Sang Woo Kim, and Youn Su Lee* \\ Department of Applied Plant Sciences, Kangwon National University, Chuncheon 24341, Republic of Korea
}

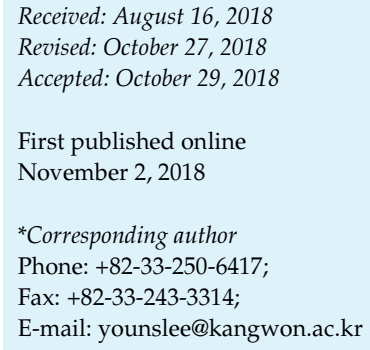

S upplementary data for this paper are available on-line only at http://jmb.or.kr.

pISSN 1017-7825, eISSN 1738-8872

Copyright(C) 2019 by

The Korean Society for Microbiology and Biotechnology
In this study, strain KNU17Pc1 was tested for its antifungal activity against Rhizoctonia solani AG-1(IA), which causes banded leaf and sheath blight (BLSB) of maize. KNU17Pc1 was tested further for its broad-spectrum antifungal activity and in vitro plant growth promoting (PGP) traits. In addition, the in vivo effects of KNU17Pc1 on reduction of BLSB severity and seedling growth promotion of two maize cultivars under greenhouse conditions were investigated. On the basis of multilocus sequence analysis (MLSA), KNU17Pc1 was confirmed as P. chlororaphis subsp. aurantiaca. The study revealed that KNU17Pc1 had strong in vitro antifungal activity and was effective toward all in vitro PGP traits except phosphate solubilization. In this study, for the first time, a strain of P. chlororaphis against Colletotrichum dematium, Colletotrichum gloeosporioides, Fusarium oxysporum f.sp.melonis, Fusarium subglutinans and Stemphylium lycopersici has been reported. Further biochemical studies showed that KNU17Pc1 was able to produce both types of phenazine derivatives, PCA and 2-OH-PCA. In addition, solid phase microextraction-gas chromatography-mass spectrometry (SPME-GC-MS) analysis identified 13 volatile organic compounds (VOCs) in the TSB culture of KNU17Pc1, 1-undecene being the most abundant volatile. Moreover, for the first time, Octamethylcyclotetrasiloxan (D4), dimethyl disulfide, 2-methyl-1,3-butadiene and 1-undecene were detected in P. chlororaphis. Furthermore, this study reported for the first time the effectiveness of $P$. chlororaphis to control BLSB of maize. Hence, further studies are necessary to test the effectiveness of KNU17Pc1 under different environmental conditions so that it can be exploited further for biocontrol and plant growth promotion.

Keywords: Biocontrol, PGPR, Pseudomonas chlororaphis, SPME-GC-MS, Zea mays

\section{Introduction}

Maize (Zea mays) is one of the most economically important food and feed crops on the planet and it is also widely used in industrial products, including starch, biofuels, beverages and oil [1]. However, several factors (both biotic and abiotic) limit the yield of maize worldwide [2,3].

Rhizoctonia solani Kühn, [teleomorph Thanatephorus cucumeris (Frank) Donk], is one of the major soil-borne pathogens of maize and it causes banded leaf and sheath blight (BLSB) disease. This plant pathogen can cause severe economic loss with up to $100 \%$ crop failure [4]. Moreover, the nature of the pathogen to infect a broad range of hosts and to survive as sclerotia under difficult environmental conditions makes the pathogen difficult to control $[4,5]$.

Biological control continues to grow in popularity and it is becoming a good alternative in reducing the use of chemicals in sustainable agriculture [6]. Plant-associated Pseudomonas spp. have been reported to have plant growth promotion, biological control activities and great potential in agro-biotechnological applications $[7,8]$. Therefore, this study aims to investigate the in vitro antagonistic activities of strain KNU17Pc1, which is isolated from maize rhizosphere, against, $R$. solani AG-1(IA) as well as other 
economically important plant fungal pathogens. The effect of volatile organic compound (VOC) emissions from strain KNU17Pc1 on the selected plant fungal pathogens was studied and the VOC profiles of strain KNU17Pc1 were further examined to investigate the chemical properties of the VOCs responsible for the observed biological activities. Furthermore, under greenhouse conditions, this study was aimed at evaluating strain KNU17Pc1 for its in vivo PGP activities and for its potential to control BLSB on two different Korean maize cultivars (Mibeak-2 and Miheugchal).

\section{Materials and Methods}

\section{Bacterial and Fungal Materials}

In this study, bacterial isolates from the rhizosphere soil of maize were isolated as described by Egamberdieva et al. [9] in 2017 at Gangwon Province ( $\left.37^{\circ} .86^{\prime} 98.83^{\prime \prime} \mathrm{N}, 127^{\circ} .75^{\prime} 07.82^{\prime \prime} \mathrm{E}\right)$, South Korea. Among morphologically different bacteria strains, strain KNU17Pc1 showing potent in vitro activity against Rhizoctonia solani AG-1(IA) was chosen. Strain KNU17Pc1 was stored at $-80^{\circ} \mathrm{C}$ in tryptic soy broth (TSB) with $20 \%$ (v/v) glycerol for long-term use. Fungal plant pathogens used in the present study were acquired from Korean Agricultural Culture Collection (KACC), Korea. The fungal plant pathogens were: Alternaria alternate (KACC43921), Colletotrichum dematium (KACC40013), Colletotrichum gloeosporioides (KACC40003), Fusarium graminearum (KACC47499), Fusarium oxysporum f.sp. melonis (KACC47669), Phytophthora capsici (KACC40157), Rhizoctonia solani AG-1(IA) (KACC40102) and Stemphylium lycopersici (KACC40967). Fusarium subglutinans was provided by Prof. Kim Kyoung Su, Kangwon National University, South Korea.

\section{In Vitro Antifungal Activity Assay}

The antifungal potential of strain KNU17Pc1 against $R$. solani AG-1(IA) was investigated using dual-culture technique on PDA at $28 \pm 2{ }^{\circ} \mathrm{C}$. After 5 days of incubation, the inhibitory activity of strain KNU17Pc1 was expressed as the length of the zone of inhibition between the fungal pathogen and the bacterial colony. In addition, the inhibitory effects of volatile compounds produced by strain KNU17Pc1 on mycelia growth of $R$. solani AG-1(IA) were determined in divided Petri plates. In brief, an aliquot ( $30 \mu \mathrm{l})$ of bacterial inoculum was simultaneously inoculated by streaking on one side of TSA agar medium and a mycelial plug of $R$. solani AG1(IA) was placed on the other side of a fresh PDA medium. After 7 days of incubation, the mycelial growth diameter was measured. Furthermore, the method of Shrestha et al. [10] was used to evaluate the inhibitory effect of strain KNU17Pc1 on germination of the sclerotia of $R$. solani AG-1(IA). To test the antifungal spectrum of strain KNU17Pc1, growth inhibition activity of strain KNU17Pc1 was tested against 8 important fungal plant pathogens. These were: A. alternate, C. dematium, C. gloeosporioides, F. graminearum, F. oxysporum f.sp. melonis, F. subglutinans, P. capsici and S. lycopersici.
The percentage of inhibition of mycelial growth of the tested fungal plant pathogens was calculated by using the following formula: $\mathrm{PI}=(\mathrm{C}-\mathrm{T}) / \mathrm{C} \times 100$, where $\mathrm{PI}$ is mycelial growth inhibition by percentage, $\mathrm{C}$ is the radial mycelial growth in control, and $\mathrm{T}$ is the radial growth of the fungal pathogens in treatment (dual culture). The experiment was conducted in completely randomized design with replications and the experiment was repeated three times.

\section{Scanning Electron Microscope (SEM) Analysis}

The interaction of the strain KNU17Pc1 with the selected plant fungal pathogens was observed by taking mycelia of the fungal pathogens from the edge of the halo zone in the dual culture plates. Samples were prepared by thin coating the sample with gold: palladium (60:40). The thin coated samples were examined under SEM (LEO Model 1450VP Variable Pressure Scanning Electron Microscope; Carl Zeiss, USA).

\section{In Vitro Assay for Antifungal Traits}

Siderophore production potential of the strain KNU17Pc1 was determined following the method of Schwyn and Neilands [11]. The potential of KNU17Pc1 for protease activity was determined by spot inoculating overnight TSB culture of KNU17Pc1 on skim milk agar and a clear zone around the bacterial colony was considered as positive [12]. The method of Ghodsalavi et al. [13] was employed to determine the lipase activity of KNU17Pc1.

\section{In Vitro Assay for Plant Growth Promoting (PGP) Attributes}

Strain KNU17Pc1 was determined for its zinc solubilization potential on PVK medium amended with an insoluble zinc source ( $\mathrm{ZnO}, 1.244 \mathrm{~g} / \mathrm{l}$ ) equivalent to $0.1 \%$ zinc. The phosphate solubilizing ability of strain KNU17Pc1 was evaluated on NBRIP (National Botanical Research Institute's phosphate growth) medium supplemented with tricalcium phosphate as a sole phosphate source. The Petri plates were incubated at $28 \pm 2^{\circ} \mathrm{C}$ for 7 days and the diameter of the clear zone around the bacterial colony was measured.

The potential of strain KNU17Pc1 to produce ammonia was determined following the method of Cappuccino and Sherman [14]. The amount of ammonia formed was determined spectrophotometrically (UV-1800, Shimadzu Corporation, Japan) using the standard curve of ammonium sulphate ranging from $0-$ $10 \mu \mathrm{mol} / \mathrm{ml}$. The method of Gordon and Weber [15] was employed to determine the potential of strain KNU17Pc1 to produce indole acetic acid (IAA). The amount of IAA concentration in the culture medium was measured using an IAA standard curve prepared by diluting pure IAA (Sigma-Aldrich, USA) in Luria-Bertani (LB) broth (Tryptone $10 \mathrm{~g}$, yeast extract $5 \mathrm{~g}$, and $\mathrm{NaCl} 10 \mathrm{~g}$ in $1 \mathrm{~L}$ of water) at different concentrations in the range of 0.05 to to $2 \mathrm{mg} / \mathrm{ml}$.

\section{Quantification of Phenazine}

Phenazines viz., phenazine-1-carboxylic acid (PCA) and 2hydroxy-phenazine-1-carboxylic acid (2-OH-PCA) were extracted 
from strain KNU17Pc1 grown in seven different media. The media were: $A B$ minimal medium [16] amended with $2 \%$ Casamino acids (Difco, Franklin Lakes, USA) (AB+CAA), King's B medium (KB) [17], LB, minimal salts medium (MSM) [18], nutrient broth (Difco Laboratories, USA), pigment production medium (PPMD) [19] and TSB. Strain KNU17Pc1 was incubated at $28 \pm 1^{\circ} \mathrm{C}$ with agitation $(180 \mathrm{rpm})$ and the bacterial culture of each medium was collected at the same O.D. The method of Maddula et al. [20] was employed to extract phenazines from KNU17Pc1. Briefly, each culture $(5 \mathrm{ml})$ was centrifuged $(2,600 \times g$ for $15 \mathrm{~min})$, and the cellfree supernatant was acidified $(\mathrm{pH}<2)$ with a concentrated $\mathrm{HCl}$. An equal volume of benzene $(\mathrm{v} / \mathrm{v})$ was added and total phenazines were extracted for $1 \mathrm{~h}$. The mixture was centrifuged and the benzene phase was separated and evaporated to dryness. The crude extract was resuspended in $0.1 \mathrm{~N} \mathrm{NaOH}$ and was quantified using UV-visible spectroscopy at $367 \mathrm{~nm}$ (PCA) and $484 \mathrm{~nm}$ (2-OH-PCA). A $0.1 \mathrm{~N} \mathrm{NaOH}$ was used as a blank. The relative amounts of PCA and 2-OH-PCA were determined using standard extinction coefficients: $\varepsilon P C A(367 \mathrm{~nm})$ of $3,019 \mathrm{M} / \mathrm{cm}$ and $\varepsilon 2-\mathrm{OH}-\mathrm{PCA}(468 \mathrm{~nm})$ of $7,943 \mathrm{M} / \mathrm{cm}$ [20].

\section{Analysis of Volatile Organic Compounds (VOCs)}

Volatile organic compounds (VOCs) from TSB liquid medium inoculated with strain KNU17Pc1 were analyzed using solid phase microextraction-gas chromatography-mass spectrometry (SPME-GC-MS) with SPME fiber assembly (CAR/PDMS) (Supelco, Inc., Bellefonte, USA). The strain KNU17Pc1 was grown in TSB liquid medium for $48 \mathrm{~h}$ in dark at $28 \pm 2{ }^{\circ} \mathrm{C}$ on a rotary shaker at $180 \mathrm{rpm}$. To prevent escaping of VOCs, a rubber stopper containing active charcoal was plugged into the test tubes. A non-inoculated TSB liquid medium was served as a control. The GC (7890A gas chromatograph, Agilent Technologies, USA) was programmed at an initial temperature of $60^{\circ} \mathrm{C}$ for $5 \mathrm{~min}$, and then gradually increased by $5^{\circ} \mathrm{C} / \mathrm{min}$ to a temperature of $325^{\circ} \mathrm{C}$ held for $50 \mathrm{sec}$. The GC transfer line was maintained at $280^{\circ} \mathrm{C}$, and detector temperature at $250^{\circ} \mathrm{C}$. Inlet pressure was $67 \mathrm{kPa}$; $\mathrm{He}, 20 \mathrm{ml} / \mathrm{min}$; filament voltage, $70 \mathrm{eV}$ ionization energy; transfer line $280^{\circ} \mathrm{C}$. The VOCs were identified by comparing the spectra mass obtained from the KNU17Pc1 sample with those from reference spectra in the Wiley 9th edition spectral libraries and National Institute of Standards and Technology 2014 V2.20 (NIST, USA, http:/ / www. nist.gov).

\section{Greenhouse Experiments}

The potential of strain KNU17Pc1 to control BLSB of maize on two commonly grown Korean maize cultivars (Mibaek-2 and Miheugchal) were carried out under greenhouse conditions. The experiment was conducted in 16-cm diameter pots filled with sterilized soil. The soil was collected from the top $30 \mathrm{~cm}$ of topsoil in Gangwon Province, South Korea. Three replications were maintained with 10 plants per replication.

\section{Preparation of Fungal and Bacterial Inoculums}

The inoculum of $R$. solani AG-1(IA) was cultured on PDA plates at $28 \pm 2^{\circ} \mathrm{C}$ for 7 days. The soil where the seeds were to be sown was removed and then two colonized PDA plugs $(8 \mathrm{~mm}$ in diameter) were replaced seven days before planting. To prevent drying of the colonized disks, they were covered with soil [21]. For bacterial inoculum preparation, the strain was grown in TSB liquid medium for $48 \mathrm{~h}$ in dark at $28^{\circ} \mathrm{C}$ on a shaker incubator at $150 \times g$. The liquid culture was centrifuged at $6,000 \times g$ for $5 \mathrm{~min}$ and the harvested bacterial cells were washed several times with a

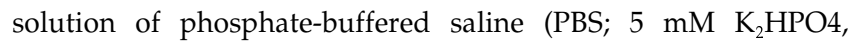
$150 \mathrm{mM} \mathrm{NaCl}, \mathrm{pH} 7.0$ ). Then, the bacterial inoculum was adjusted to a concentration of $10^{8}$ cells $/ \mathrm{ml}^{-1}$. Seeds of both cultivars were surface-sterilized in $2 \%$ sodium hypochlorite for $2 \mathrm{~min}$, followed by $70 \%$ ethanol for $2 \mathrm{~min}$, and finally rinsed several times in sterile distilled water. Maize seeds (10) of each cultivar were soaked separately into the bacterial suspensions $(10 \mathrm{ml})$ and were incubated at $28 \pm 2{ }^{\circ} \mathrm{C}$ for $12 \mathrm{~h}$ in a rotary shaker at $150 \times g$. Subsequently, seeds of each cultivar were air-dried in a laminar air-flow at ambient temperature and one seed per pot was planted. Non-treated plants (neither R. solani AG-1(IA), nor strain KNU17Pc1) served as positive control and plants inoculated only with $R$. solani AG-1(IA) were served as negative control.

\section{Disease Assessment}

The potential of strain KNU17Pc1 on reduction of disease severity (DS) of BLSB of maize was assessed at 30 days after planting and the DS was recorded using a 1-5 scale [22]. For analysis, the scale was converted into a percentage severity index (PSI) [23].

$$
\text { PSI }=\frac{\sum \text { of all numerical ratings } \times 100}{\text { Total number of observations } \times \text { maximum score on scale }}
$$

\section{Plant Growth Promotion Assessment}

The physical plant growth characteristics such as plant height and stem circumference of maize plants were measured. In addition, data regarding total chlorophyll content (SPAD unit) of were measured using chlorophyll-meter SPAD 502 (Konica Minolta, Japan) 30 days after planting (DAP). Maize seedlings were collected at $30 \mathrm{DAP}$ and morphological data viz., dry weights of shoot and root $\left(65^{\circ} \mathrm{C}, 72 \mathrm{~h}\right.$ electric oven) and leaf number were taken. Three replications were maintained with 10 plants per replication.

\section{Molecular Characterization}

Identification of strain KNU17Pc1. The genomic DNA of strain KNU17Pc1 was isolated using the HiYield Genomic DNA Mini Kit (Real Biotech Corporation, Taiwan) following the manufacturer's instructions. PCR amplification of the 16S rRNA gene was performed using universal primers 27f (5'-AGAGTTTGATCA TGGCTCAG-3') and 1492R (5'-TACGGYTACCTTGTTACGACTT$\left.3^{\prime}\right)$. Sequencing was performed at Macrogen Inc. (Korea) using a 3730XL DNA sequencer (Applied BioSystems, USA). Furthermore, Multilocus Sequence Analysis (MLSA) was employed to charac- 


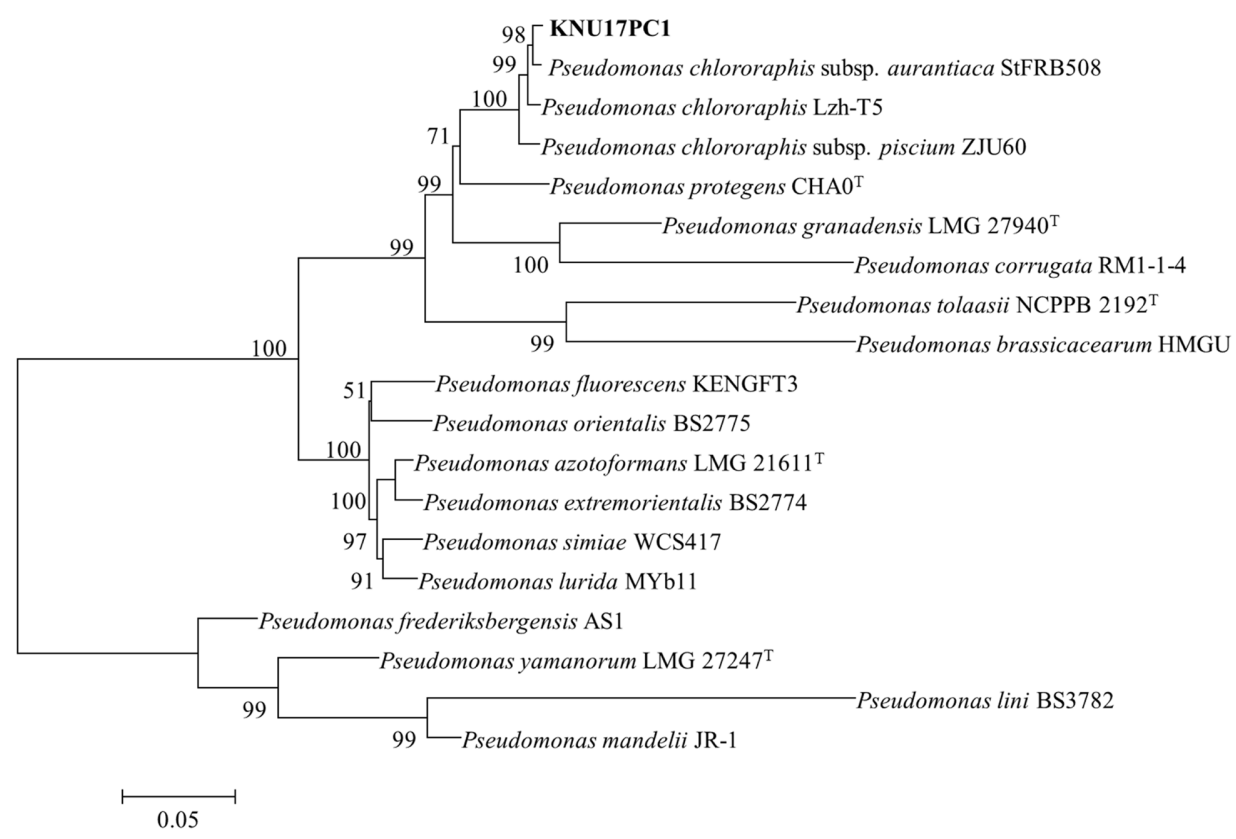

Fig. 1. Phylogenetic tree based on concatenated nucleotide sequences of seven housekeeping genes from strain KNU17Pc1 and some type and reference.

Bootstrap values $(>50 \%)$ based on 1,000 trials are shown at branch nodes. Sequences of type species are indicated by a symbol (T).

terize the strain KNU17Pc1 using primers of seven housekeeping gene fragments as described by Andreani et al. [28]. The sequences of the seven housekeeping gene fragments were concatenated in the following order: ileS (596), glnS (500), gyrB (645), nuoD (719), recA (488), rpoB (540) and rpoD (565). The sequences of partial $16 \mathrm{~S}$ rRNA and the remaining seven housekeeping gene were subjected to BLAST analysis and compared with their respective previously published gene sequences found in the NCBI server (http://www.ncbi.nlm.nih.gov). Phylogenetic analysis was performed by neighbor-joining method using MUSCLE implemented in the program MEGA version 6 [24]. Similarly, the concatenated sequences (4053 bp) were used to construct a phylogenetic tree using MEGA version 6 [24]. The analysis was carried out with 1,000 bootstrap replications.

\section{Detection of phzE Gene}

The strain KNU17Pc1 was subjected to PCR targeting the phenazine (phzE) gene, which is involved in antifungal activity [8, 25]. The pair of primers and PCR conditions for phzE were performed as previously described [26] and a Zymoclean Gel DNA Recovery Kit (Zymo Research) was used to gel purify the PCR products. Sequence analysis of the PCR products was performed with their respective designed primers at Macrogen Inc. (Korea) using a 3730XL DNA sequencer (Applied BioSystems).

\section{Genbank Accession Numbers}

The 16S rRNA gene sequences of the strain KNU17Pc1 have been deposited in the NCBI's GenBank under accession number
MH182498. The sequences of MLSA loci of the strain have been deposited in the GenBank under accession numbers MH568738 (ileS), MH568736 (glnS), MH568737 (gyrB), MH568739 (nuoD), MH568740 (recA), MH568741 (rpoB) and MH568742 (rpoD). The sequence data of the phzE gene of strain KNU17Pc1 was submitted to Genbank and can be found under accession number, MH388419.

\section{Data Analysis}

The experimental data were subjected to analysis of variance (ANOVA) using SAS software version 9.2 [27]. All experiments were replicated at least three times and the results were expressed as mean \pm standard error. Means were separated using Duncan's Multiple Range Test (DMRT) at $p \leq 0.05$.

\section{Results}

\section{Identification of Strain KNU17Pc1}

Pairwise sequence analysis indicated that of the $16 \mathrm{~S}$ rRNA nucleotide sequence of strain KNU17Pc1 shared high similarity (99.0-100\%) with reference species of Pseudomonas. The phylogenetic relationship using the 16S rRNA gene sequence placed the strain KNU17Pc1 within the $P$. chlororaphis cluster in our phylogenetic tree (Fig. S1). More importantly, a multilocus sequence analysis (MLSA) was employed for further identification. The phylogenetic analysis based on the concatenated sequences of seven 
Table 1. Antifungal activity of Pseudomonas chlororaphis strain KNU17Pc1.

\begin{tabular}{lcc}
\hline \multirow{2}{*}{ Target pathogens } & \multicolumn{2}{c}{ Percent inhibition zone $(\mathrm{mm})^{\mathrm{a}}($ Mean \pm SE $)$} \\
\cline { 2 - 3 } & Diffusible $^{\mathrm{b}}$ & Volatile $^{\mathrm{c}}$ \\
\hline A. alternate & $45.4 \pm 2.4^{\mathrm{a}}$ & $48.7 \pm 1.2^{\mathrm{cd}}$ \\
C. dematium & $45.4 \pm 1.3^{\mathrm{a}}$ & $45.8 \pm 1.6^{\mathrm{d}}$ \\
F. oxysporum f.sp. melonis & $43.9 \pm 1.0^{\mathrm{ab}}$ & $19.1 \pm 0.9^{\mathrm{f}}$ \\
P. capsici & $41.0 \pm 0.8^{\mathrm{abc}}$ & $46.8 \pm 2.1^{\mathrm{cd}}$ \\
C. gloeosporioides & $37.8 \pm 1.3^{\mathrm{cd}}$ & $51.9 \pm 0.8^{\mathrm{c}}$ \\
S. lycopersici & $39.1 \pm 2.2^{\mathrm{bcd}}$ & $76.2 \pm 3^{\mathrm{b}}$ \\
R. solani AG-1(IA) & $35.9 \pm 0.9^{\mathrm{cd}}$ & $89.2 \pm 4.2^{\mathrm{a}}$ \\
F. subglutinans & $35.5 \pm 1.2^{\mathrm{cd}}$ & $33.9 \pm 0.9^{\mathrm{e}}$ \\
F. graminearum & $35.1 \pm 0.7^{\mathrm{d}}$ & $29.6 \pm 0.7^{\mathrm{e}}$ \\
\hline
\end{tabular}

${ }^{a}$ Values are means of three replications.

${ }^{\mathrm{b}}$ The antifungal activity determined using dual-culture assay.

'The antifungal activity determined using volatile metabolite assays (assays on divided Petri plates).

Means followed by the same letter (s) within a column are not significantly different $(p \leq 0.05)$, DMRT.

housekeeping genes revealed that strain KNU17Pc1 belongs to $P$. chlororaphis subsp. aurantiaca and it was diverged from the other closely related species of the $P$. chlororaphis cluster (Fig. 1).

\section{In Vitro Antagonism and Sclerotial Germination Assay}

In the dual-culture assay, strain KNU17Pc1 was capable to inhibit the growth of $R$. solani AG-1(IA) (Table 1 and Fig. 2). The strain was also able to completely curb the germination of sclerotia of $R$. solani AG-1(IA) in a sclerotial germination test even after a long period of incubation (data not shown). The strain was further tested in a dual culture assay for its activity against 8 economically important phytopathogens. The results showed that the strain had strong antifungal activity against all the tested fungi (Table 1 and Fig. 2). The strain KNU17Pc1 showed the highest growth inhibition effect against $A$. alternate and C. dematium. In the volatile metabolite assays (assays on divided Petri plates), strain KNU17Pc1 showed high inhibitory effect against $R$. solani AG-1(IA) and other important plant fungal pathogens (Table 1 and Fig. S2).

\section{SEM Analysis}

The effect of $P$. chlororaphis strain KNU17Pc1 on the mycelial morphology of $R$. solani AG-1(IA) and the selected plant fungal pathogens were examined under scanning electron microscope by observing the mycelia found along the edges of the inhibitory halo zone. Microscopic examination showed that KNU17Pc1 caused significant changes in the hypha morphology of all the selected plant pathogens compared to the untreated control. The strain caused the hyphae of $R$. solani AG-1(IA) to lyse and deform (Fig. 3). In addition, the strain was capable of causing substantial change in hyphal morphology of A. alternate, $F$. graminearum and F. oxysporum f.sp. melonis (Fig. 3).

\section{Characterization of In Vitro Antifungal and PGP Traits of KNU17Pc1}

Strain KNU17Pc1 was found to be positive for zinc

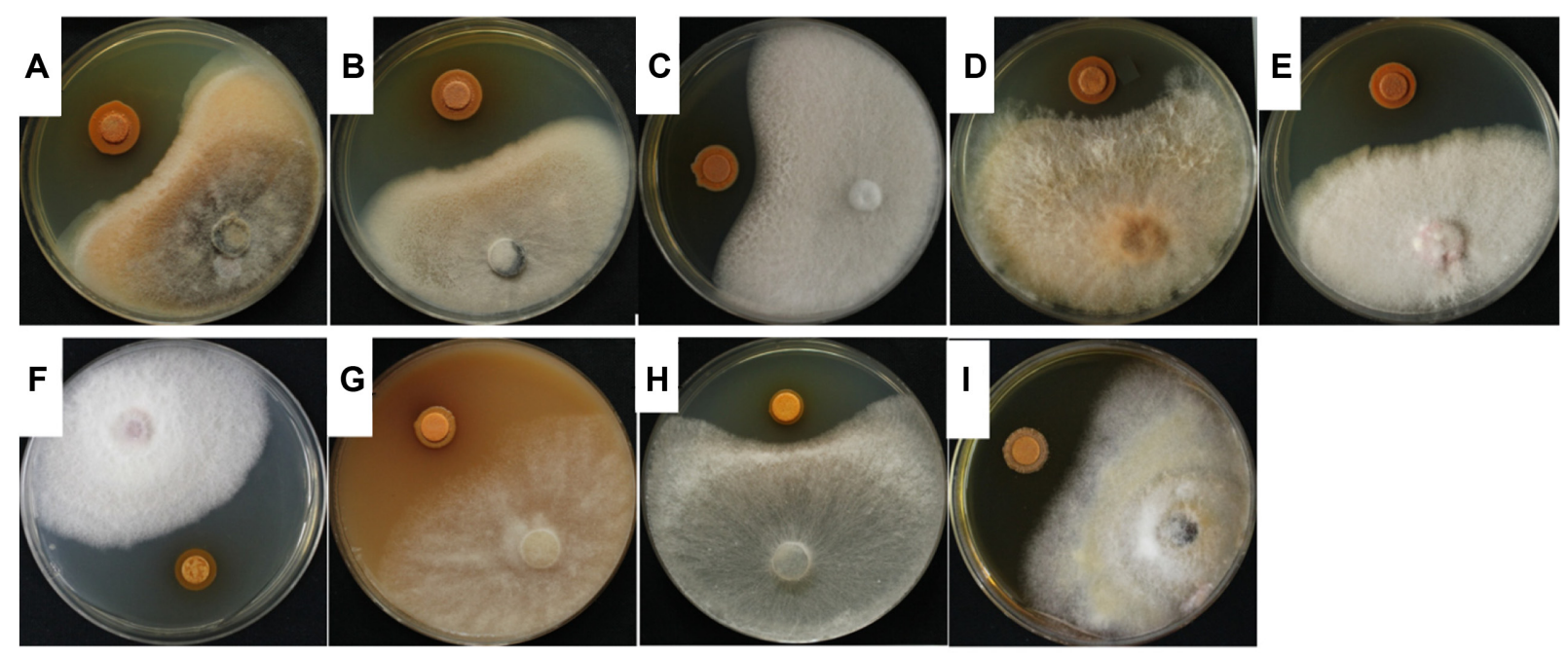

Fig. 2. Antifungal activity of Pseudomonas chlororaphis strain KNU17Pc1 against different plant pathogens from dual culture assay (diffusible metabolites): (A) A. alternate, (B) C. dematium, (C) C. gloeosporioides, (D) F. graminearum, (E) F. oxysporum f.sp. melonis, (F), F. subglutinans, (G), P. capsici, (H) R. solani AG-1(IA), (I) S. lycopersici. 

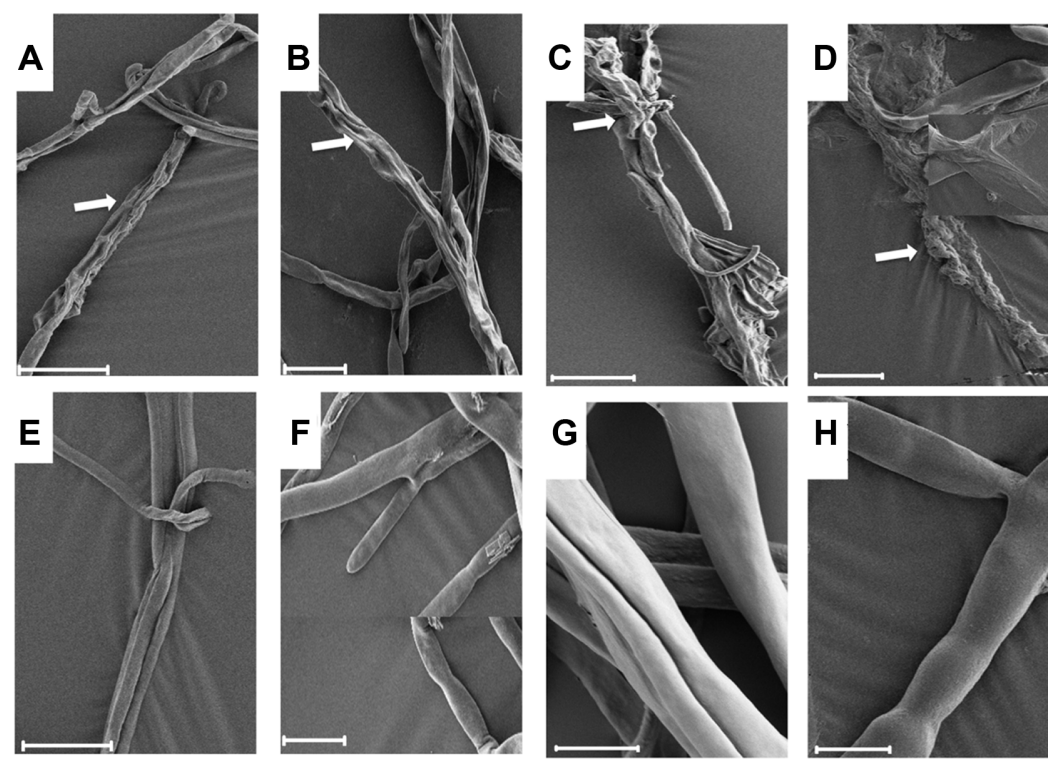

Fig. 3. Scanning electron micrographs of (A and $\mathbf{E})$ A. alternate, (B and $\mathbf{F})$ F. graminearum, $(\mathbf{C}$ and $\mathbf{G})$ F. oxysporum f.sp. melonis and (D and H) R. solani AG-1(IA) (top = treated with KNU17Pc1, bottom = control), (scale bars: $10 \mu \mathrm{m})$. A. white arrows indicate deformed and/or lysed fungal structures.

solubilization, siderophore production and extracellular activities. However, KNU17Pc1 had no phosphate solubilization or amylase activity (data not shown). In the ammonia production test, KNU17Pc1 showed positive results for ammonia production after $72 \mathrm{~h}$ of incubation (data not shown). The amount of ammonia produced in peptone water was $9 \mu \mathrm{mol} / \mathrm{ml}$. The ability of KNU17Pc1 to produce IAA was tested in LB medium amended with L-tryptophan at various concentrations ranging from 0.05 to $2.0 \mathrm{mg} / \mathrm{ml}$. The study showed that KNU17Pc1 produced $11 \mu \mathrm{g} / \mathrm{ml}$ of IAA at higher L-tryptophan concentration $(2 \mathrm{mg} / \mathrm{ml})$ after $72 \mathrm{~h}$ of incubation (Fig. S3).

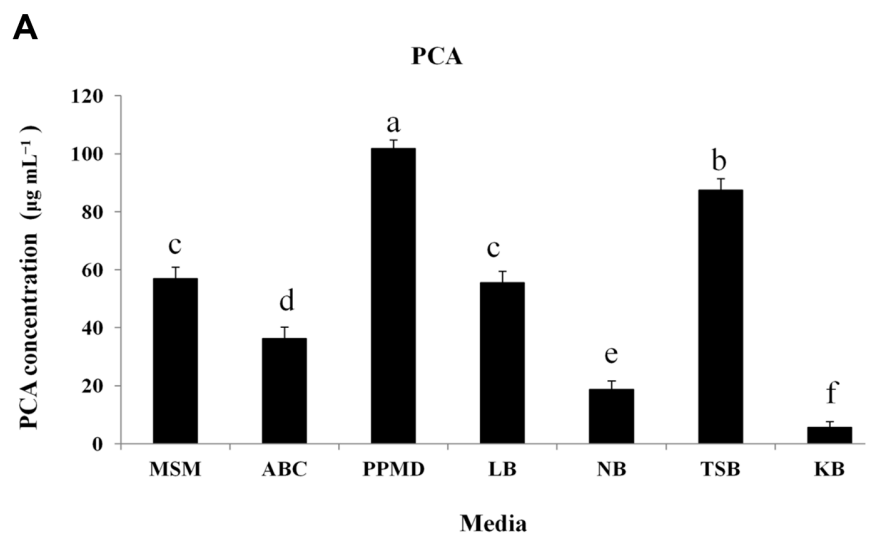

\section{Quantification of PCA and 2-OH-PCA}

The result of the present study revealed that strain KNU17Pc1 was capable of producing both types of phenazine derivatives, PCA and 2-OH-PCA (Figs. 4A and 4B). PCA and 2-OH-PCA production by KNU17Pc1 was tested when the bacterial culture of each tested media reached the same O.D. The maximum amount of PCA and 2-OH-PCA was recorded in PPMD broth $\left(101.8 \mu \mathrm{g} / \mathrm{ml}^{-1}\right.$ and $9.5 \mu \mathrm{g} / \mathrm{ml}^{-1}$, respectively) followed by TSB broth $\left(87.4 \mu \mathrm{g} / \mathrm{ml}^{-1}\right.$ and $5.6 \mu \mathrm{g} / \mathrm{ml}^{-1}$, respectively). On the other hand, a lower amount of PCA and 2-OH-PCA was recorded in King's medium $B\left(5.8 \mu \mathrm{g} / \mathrm{ml}^{-1}\right.$ and $0.5 \mu \mathrm{g} / \mathrm{ml}^{-1}$, respectively).

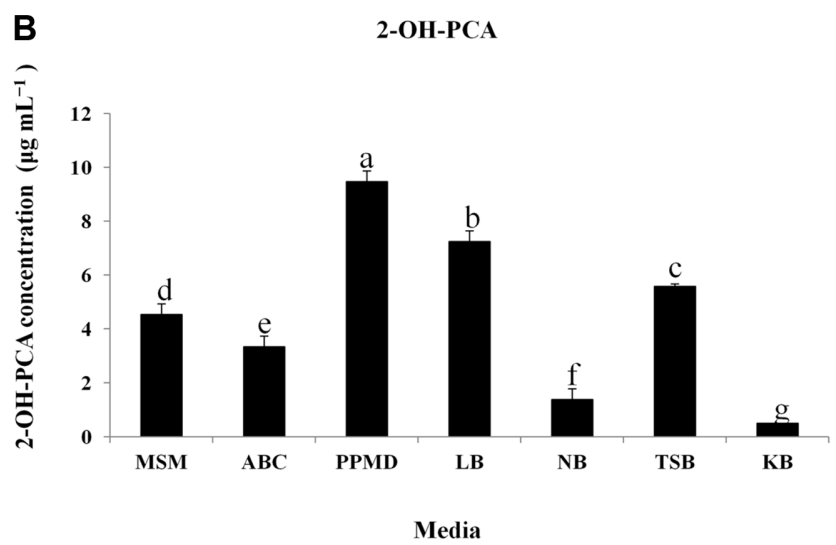

Fig. 4. Production of (A) PCA and (B) 2-OH-PCA of strain KNU17Pc1 grown in seven different liquid media. 


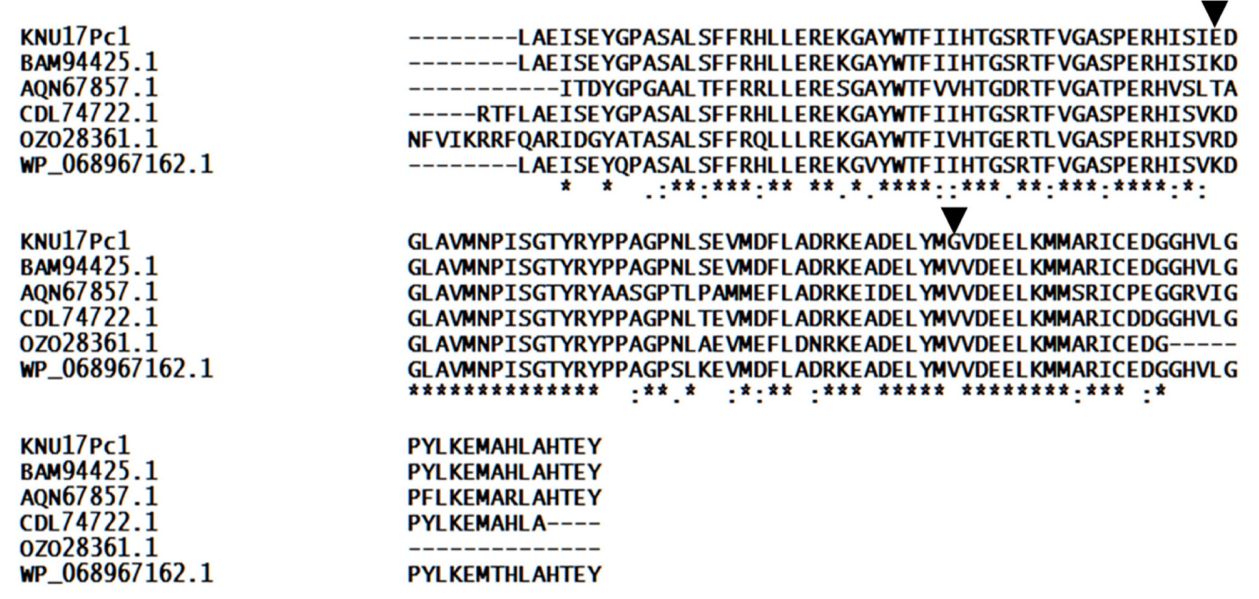

Fig. 5. Sequence analysis of phenazine biosynthesis protein (phzE gene) of $P$. chlororaphis strain KNU17Pc1 (KNU17Pc1), P. chlororaphis subsp. aurantiaca (BAM94425.1), P. chlororaphis (CDL74722.1), P. aeruginosa (OZO28361.1), P. fluorescens (WP_068967162.1), Streptomyces cyaneofuscatus (AQN67857.1).

$\boldsymbol{\nabla}$ Distinct amino acid pointing to $P$. chlororaphis subsp. aurantiaca. *Fully conserved residue. :Highly conserved column. Weakly conserved column. Gaps are shown as dashes.

\section{Detection of Phenazine Biosynthesis (phzE) Gene by PCR Amplification}

In this study, we tested if our strain KNU17Pc1 carries phzE, which catalyzes the first step in the biosynthesis of PCA and other phenazines [24, 25]. The results of PCR using specific primers revealed the gene that codes for phzE (phenazine) was successfully amplified from strain KNU17Pc1 with the expected band size of 450 bp (Fig. S4). Furthermore, pairwise sequence analysis showed that nucleotide sequences of phzE (Acc. No. MH388419) from KNU17Pc1 showed high sequence similarities (99\%) to the gene of $P$. chlororaphis subsp. aurantiaca involved in phenazine (Acc. No. AB794886.1). The deduced amino-acid sequences of phzE from KNU17Pc1 also revealed very high sequence identity (98\%) with previously reported phenazine phzE amino-acid sequences of $P$. chlororaphis (Acc. No. BAM94425.1), with only a two-amino-acid residue difference (Fig. 5).

\section{Identification of Volatile Compounds (VOCs) from Strain KNU17Pc1}

In this study, VOCs emitted from strain KNU17Pc1 grown in TSB media were analyzed by SPME-GC-MS. The volatile compound profiles produced by the strain KNU17Pc1 were compared with the volatile compounds found in the bacteria in the non-inoculated medium (control). The results revealed that there was a very clear separation between control and strain KNU17Pc1 as

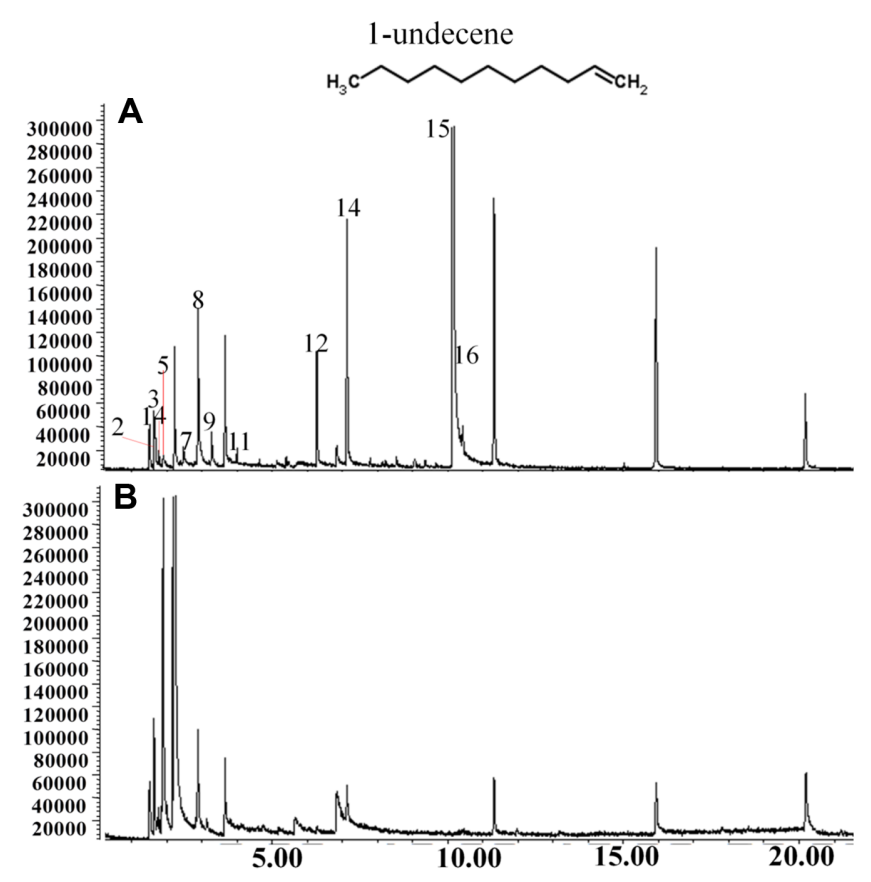

Fig. 6. Chromatographic profiles of VOCs of (A) P. chlororaphis strain KNU17Pc1 incubated for $24 \mathrm{~h}$ in TSB medium (B) noninoculated TSB medium.

The VOCs were as follows: (1) 1,4-Bis(trimethylsilyl)benzene, (2) propanoate, (3) 2-methyl-1,3-butadiene, (4) 1-Dimethylisopropylsilyloxy3-methylbut-2-ene, (5) Acetaldehyde methyl hydrazone, (7) NMethylthiourea, (8) Dimethyl disulfide, (9) 2-Amino-1H-benzimidazole, (11) 1,4-Bis(trimethylsilyl)benzene, (12) 5H-Naphtho[2,3-b]carbazole, (14) Octamethylcyclotetrasiloxan, (15) 1-undecene and (16) 1,1,3,3,5,5,7,7,9,9-decamethylpentasiloxane. 

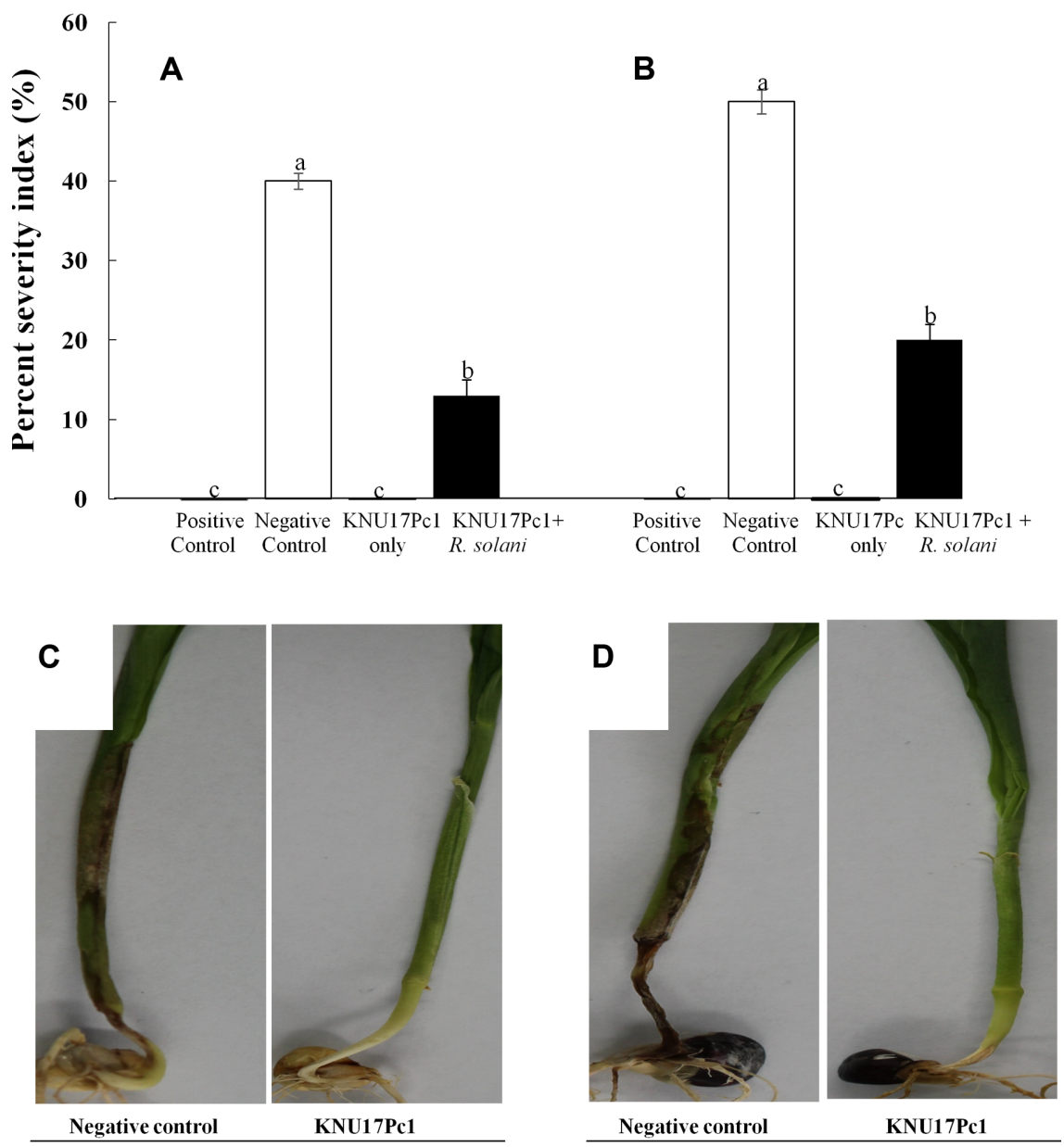

Mibaek-2

Miheugchal

Fig. 7. Effect of seed inoculation with strain KNU17Pc1 on BLSB percent severity index of (A) Mibaek-2 and (B) Miheugchal under greenhouse conditions of artificial infestation with $R$. solani AG-1(IA). Percent severity index (mean of three replications) assessed 30 days after planting. Pictorial view of 7 days old (C) Mibaek-2 and (D) Miheugchal seedlings (left = negative control, right $=$ treated with strain KNU17Pc1). Non-inoculated plants (neither the pathogen (R. solani AG-1(IA)), nor KNU17Pc1 strain) served as positive control and plants inoculated only with $R$. solani AG-1(IA) served as negative control.

indicated in Fig. 7. A total of 13 different emitted VOCs of strain KNU17Pc1 origin, which were absent in control, were identified (Fig. 6). The 1-undecene having high abundant peak $(45.7 \%)$ with RT 10.15 was the most abundant volatile in strain KNU17Pc1.

\section{Greenhouse Experiments}

Effect of strain KNU17Pc1 on disease severity in maize seedlings. Strain KNU17Pc1 was able to suppress the severity of BLSB on both Korean maize cultivars (Miheugchal and Mibaek-2). KNU17Pc1 was efficient (64.1\% and 69\% for Mhengchal and Mibaek-2, respectively) in reducing the disease compared to the control. To the contrary, seedlings inoculated only with $R$. solani AG-1(IA) (negative control) were highly blighted in both cultivars by the artificially inoculated $R$. solani AG-1(IA) (Fig. 7). As expected, nontreated plants (neither the pathogen ( $R$. solani AG-1(IA)), nor strain KNU17Pc1) of both cultivars showed no evidence of disease symptoms on both cultivars.

Plant growth promotion activity of strain KNU17Pc1. The results of the greenhouse experiment revealed that KNU17Pc1 had promising results in promoting the growth of both maize cultivars (Figs. 8 and 9). Strain KNU17Pc1 significantly $(p \leq 0.05)$ increased shoot and root dry 

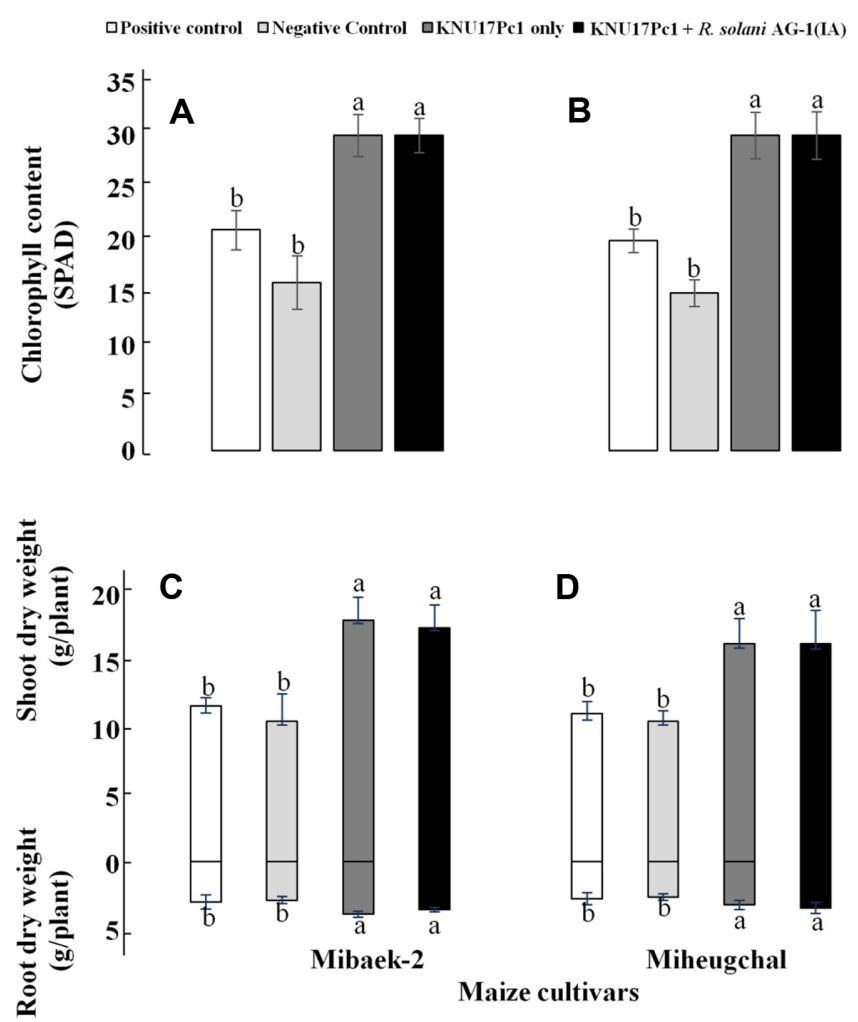

Fig. 8. Effect of strain KNU17PC1 on the seedling growth performance of two maize cultivars after 30 days grown under greenhouse conditions.

(A and B) total chlorophyll content of Mibaek-2 and Miheugchal, (C and D) seedling dry weight of Mibaek-2 and Miheugchal, respectively. Non-inoculated plants (neither the pathogen (R. solani AG-1(IA)), nor KNU17Pc1 strain) served as positive control and plants inoculated only with $R$. solani AG-1(IA) served as negative control.

weight of Mibaek-2 and Miheugchal compared to negative control (plants inoculated only with $R$. solani AG-1(IA)) (Fig. 8). Regarding the number of leaves, the strain showed insignificant differences compared to non-bacterized controls in both cultivars, (data not shown). The total chlorophyll content in the un-bacterized negative control of both cultivars was reduced while bacterized plants of both cultivars were significantly improved (Fig. 8). Furthermore, in both maize cultivars, seed inoculation with strain KNU17Pc1 led to a significant increase in the plant height of the seedlings along with an increase in stem diameter when compared to their respective non-bacterized controls (Fig. 9).

\section{Discussion}

Plant-associated Pseudomonas spp. have been reported to have great potential for plant growth promotion and plant disease management $[7,8]$. Therefore, we isolated a multitrait, plant growth-promoting rhizobacteria (PGPR), strain KNU17Pc1. Based on 16S RNA and MLSA analysis, the results revealed that KNU17Pc1 belongs to P.chlororaphis subsp. aurantiaca. In keeping with this finding, Andreani et al. [28] discussed that the MLSA approach has high discrimination power in all the taxa including Pseudomonas. Strain KNU17Pc1 suppressed the mycelial growth and germination of sclerotia of $R$. solani AG-1(IA). Management of BLSB is difficult due to sclerotia formation which can overwinter in very harsh environmental conditions and continue cycling infection $[29,30]$. Hence, the potential of the KNU17Pc1 in inhibiting the germination of sclerotia of R. solani AG-1(IA) has huge implications in the sustainable BLSB management of maize. The effect of plant growthpromoting bacteria in inhibiting sclerotial germination of R. solani AG-1(IA) has previously been reported [31, 32], however, the potential of Pseudomonas chlororaphis was not reported. In addition, the strain showed strong antifungal activity against all the tested fungi in the in vitro antagonism tests, dual culture and volatile metabolite assays. The zone of inhibition around tested plant pathogens by KNU17Pc1 may be linked to the strain's ability to produce secondary metabolites like phenazine, ammonia, and proteolytic enzymes [26, 33, 34]. Interestingly, this is the first report of P.chlororaphis against C.dematium, C. gloeosporioides, F. oxysporum f.sp. melonis, F. subglutinans and S. lycopersici. F. subglutinans is the potential cause of mycotoxin contamination [35] and also causes seedling blight and stalk rot of maize that poses a potential risk to maize production [36]. Furthermore, C.dematium, C. gloeosporioides, F. oxysporum f.sp. melonis and S. lycopersici are among the most economically important pathogens of crops [37-39]. This connotes the essentiality for exploitation of KNU17Pc1 for the management of $C$. dematium, C. gloeosporioides, F. oxysporum f.sp. melonis, F. subglutinans and S. lycopersici. Microscopic examination showed that KNU17Pc1 caused hyphae of R. solani AG-1(IA), A. alternate, F. graminearum and F. oxysporum f.sp. melonis to lyse and deform. Similar to the present study, Huang et al. [40] reported abnormal morphological changes in $R$. solani AG-1(IA) by different biocontrol agents. To the best of our knowledge, the injurious effects of P.chlororaphis on F.oxysporum f.sp. melonis have not previously been investigated.

Production of pigments in a medium is an indication of bacteria producing metabolites [8]. The present study revealed the potential of strain KNU17Pc1 to produce both types of phenazine derivatives, PCA and 2-OH-PCA. In 

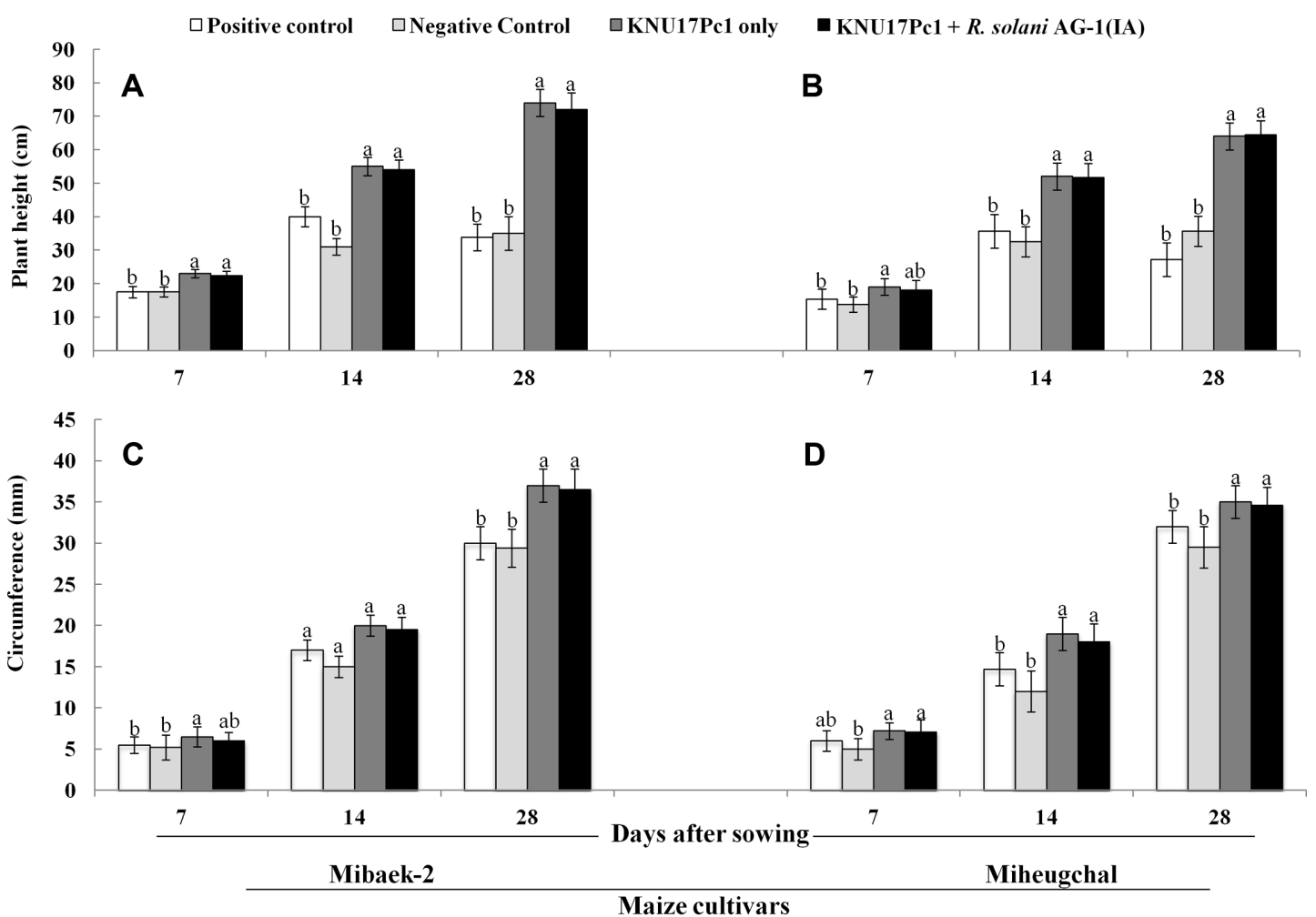

Fig. 9. Effect of strain KNU17Pc1 on the seedling growth performance of two maize cultivars within 30 days grown under greenhouse conditions.

(A and B) plant height of Mibaek-2 and Miheugchal, (C and D) circumference of Mibaek-2 and Miheugchal seedling in positive control, negative control, KNU17Pc1 only and strain KNU17Pc1+R. solani AG-1(IA), respectively. Non-inoculated plants (neither the pathogen (R. solani AG-1(IA)), nor KNU17Pc1 strain) served as positive control and plants inoculated only with $R$. solani AG-1(IA) served as negative control.

agreement with this report, previous studies [19, 41-43] reported the potential of $P$. chlororaphis to produce phenazine derivatives PCA and 2-OH-PCA. The maximum PCA yield in PPMD and TSB broth may be attributed to the presence of glucose and soy peptone, respectively. Similar to our report, He et al. [44] reported that glucose and soy peptone as carbon and nitrogen source, respectively were the most important factors for PCA production. The very low amounts of PCA production by P. chlororaphis in King's medium B has also been previously reported by Chin-AWoeng et al. [45].

The phenazine biosynthesis (phzE) gene, which codes for aminodeoxyisochorismate synthase, is involved in the biosynthesis of biologically secondary metabolites and plays vital roles in biological control [46, 47]. In this study, nucleotide sequences of phzE (Acc. No. MH388419) and deduced amino-acid sequences of phzE open reading frame (ORF) from KNU17Pc1 showed high sequence similarities $(99 \%)$ to the phenazine gene (Acc. No. AB794886.1) and phenazine phzE amino-acid sequences (Acc. No. BAM94425.1) of $P$. chlororaphis subsp. aurantiaca.

Previous studies $[48,49]$ reported that 1 -undecene, having strong antifungal activity, was the main active compound emitted by P. fluorescens. Similarly, in our SPME-GC-MS analysis 1-undecene was the most abundant volatile in P. chlororaphis strain KNU17Pc1. Antifungal activity of 1undecene against $R$. solani has previously been reported [50]. Nevertheless, this is the first report on emission of 1undecene by $P$. chlororaphis. The Octamethylcyclotetrasiloxan (D4), which is volatile methyl siloxanes, has been reported to have antibacterial and antifungal activity [51] and was found in the present study. For the first time, 2-methyl-1,3butadiene and dimethyl disulfide (DMDS) were detected in Pseudomonas chlororaphis. The 2-methyl-1,3-butadiene is an important biogenic hydrocarbon in reducing reactive oxygen species (ROS) including hydroxyl anions $\left(\mathrm{OH}^{-}\right)$and hydrogen peroxide $\left(\mathrm{H}_{2} \mathrm{O}_{2}\right)$ in plant cells [52, 53]. The beneficial effect of DMDS for plant fungal disease suppression and growth promotion has been previously reported $[40,54,55]$. 
In the in vitro PGP traits assay, similar to previous reports [56, 57], strain KNU17Pc1 was positive for zinc solubilization and negative for phosphate solubilization. In agreement with our result, the potential of $P$. chlororaphis to produce IAA has been previously reported [9] while other studies [8] noted that $P$. chlororaphis did not produce IAA. In addition, strain KNU17Pc1 produced a high amount $(9 \mu \mathrm{mol} / \mathrm{ml})$ of ammonia in peptone water. Our result complies with previous reports [58] that several Pseudomonas species produce ammonia. Previous studies [34,59] discussed that inorganic volatiles like ammonia have been found to suppress the growth of plant fungal pathogens. In addition, ammonia-producing strains have a key role in the nutritional needs of plants by accumulation of nitrogen and offering ammonia to nearby plants by breaking up complex nitrogenous materials [60].

Similar to the result of our in vitro assay for antifungal traits, production of siderophores, protease and lipase by Pseudomonas chlororaphis has been previously reported [8]. However, KNU17Pc1 was amylase negative [8]. Previous studies $[41,61]$ discussed that production of siderophores offers beneficial microbes a competitive advantage to suppress the rise of plant pathogens and also help the surrounding plants to obtain iron for optimal growth. These hydrolytic enzymes were found to play a key role in fungal cell walls degradation, which indirectly promotes plant growth [45].

The results of greenhouse experiments showed that strain KNU17Pc1 was able to protect both cultivars from BLSB on artificially infested soil with $R$. solani AG-1(IA). The previous study [62] reported that BLSB was effectively controlled by $P$. fluorescens. Nevertheless, this is the first research report on the efficacy of $P$. chlororaphis in suppressing the disease severity of BLSB on maize. This may be partly due to the strong antifungal activity of P. chlororaphis against $R$. solani AG-1(IA) in the soil. Similar to our study, previous reports $[63,64]$ indicated that treating maize seeds with plant growth-promoting bacteria Pseudomonas species promoted plant growth. The beneficial effect of the strain KNU17Pc1 on plant growth promotion of maize cultivars may be attributed to the direct plant growth promoting effect of the strain [65] and may be indirectly due to the antagonistic nature of the strain in influencing the growth of mycelia and germination of sclerotia of $R$. solani [66]. In addition, the significant growth reduction of maize seedlings in the negative control of Mibaek-2 and Miheugchal may be partly due to infection caused by $R$. solani [67]. Therefore, further studies are needed to evaluate the wide-range biocontrol activities of strain KNU17Pc1 against economically important plant fungal pathogens under field conditions.

\section{Acknowledgment}

This research was financially supported by the University Industry Cooperation Foundation of Kangwon National University.

\section{Conflict of Interest}

The authors have no financial conflicts of interest to declare.

\section{References}

1. Shiferaw B, Prasanna BM, Hellin J, Bänziger M. 2011. Crops that feed the world 6. Past successes and future challenges to the role played by maize in global food security. Food Security 3: 307.

2. Castiglioni P, Warner D, Bensen RJ, Anstrom DC, Harrison J, Stoecker M, et al. 2008. Bacterial RNA chaperones confer abiotic stress tolerance in plants and improved grain yield in maize under water-limited conditions. Plant Physiol. 147: 446-455.

3. Ramachandiran K, Pazhanivelan S. 2016. Abiotic factors (nitrogen and water) in maize: a review. Agric. Rev. 37: 317-324.

4. Hooda KS, Khokhar MK, Parmar H, Gogoi R, Joshi D, Sharma SS, et al. 2017. Banded leaf and sheath blight of maize: historical perspectives, current status and future directions. Proc. Natl. Acad. Sci., India Sect. B Biol. Sci. 87: 1041-1052.

5. Groth DE, Bond JA. 2006. Initiation of rice sheath blight epidemics and effect of application timing of azoxystrobin on disease incidence, severity, yield, and milling quality. Plant Dis. 90: 1073-1076.

6. Compant S, Duffy B, Nowak J, Clement C, Barka, E. 2005. Use of plant growth-promoting bacteria for biocontrol of plant diseases: principles, mechanisms of action and future prospects. Appl. Environ. Microbiol. 71: 4951-4959.

7. Duke KA, Becker MG, Girard IJ, Millar JL, Fernando WD, Belmonte MF, et al. 2017. The biocontrol agent Pseudomonas chlororaphis PA23 primes Brassica napus defenses through distinct gene networks. BMC Genomics 18: 467.

8. Jain R, Pandey AA. 2016. phenazine-1-carboxylic acid producing polyextremophilic Pseudomonas chlororaphis (MCC2693) strain, isolated from mountain ecosystem, possesses biocontrol and plant growth promotion abilities. Microbiol. Res. 190: 63-71.

9. Egamberdieva D, Jabborova D, Hashem A. 2015. Pseudomonas induces salinity tolerance in cotton (Gossypium hirsutum) and resistance to Fusarium root rot through the modulation of indole-3-acetic acid. Saudi J. Boil. Sci. 22: 773-779. 
10. Shrestha BK, Karki HS, Groth DE, Jungkhun N, Ham JH. 2016. Biological control activities of rice-associated Bacillus sp. strains against sheath blight and bacterial panicle blight of rice. PLoS One 11: e0146764.

11. Schwyn B, Neilands JB. 1987. Universal chemical assay for the detection and determination of siderophores. Anal. Biochem. 160: 47-56.

12. Smibert RM, Krieg NR. 1994. Phenotypic Characterization. In Gerhardt P, Murray RGE, Wood WA, Krieg NR (eds.), Methods for General and Molecular Bacteriology, pp. 607-654. American Society for Microbiology, Washington, D.C

13. Ghodsalavi B, Ahmadzadeh M, Soleimani M, Madloo PB, Taghizad-Farid R. 2013. Isolation and characterization of rhizobacteria and their effects on root extracts of Valeriana officinalis. Austr. J. Crop Sci. 7: 338-344.

14. Cappuccino JG, Sherman N. 1996. pp. 186. $4^{\text {th }}$ Ed. Microbiology: A Laboratory Manual. The Benjamin/cummings Publishing Co., Inc., Menlo Park, California.

15. Gordon SA, Weber RP. 1951. Colorimetric estimation of indoleacetic acid. Plant Physiol. 26: 192-195.

16. Pamp SJ, Tolker-Nielsen T. 2006. Multiple roles of biosurfactants in structural biofilm development by Pseudomonas aeruginosa. J. Bacteriol. 189: 2531-2539.

17. Pierson III LS, Thomashow LS. 1992. Cloning and heterologous expression of the phenazine biosynthetic. Mol. Plant Microbe Interact. 5: 330-339.

18. Davis BD, Mingioli ES. 1950. Mutants of Escherichia coli requiring methionine or vitamin B12. J. Bacteriol. 60: 17-28.

19. Wood DW, Gong F, Daykin MM, Williams P, Pierson L. 1997. N-acyl-homoserine lactone-mediated regulation of phenazine gene expression by Pseudomonas aureofaciens 30-84 in the wheat rhizosphere. J. Bacteriol. 179: 7663-7670.

20. Maddula VSRK, Pierson E A, Pierson III LS. 2008. Altering the ratio of phenazines in Pseudomonas chlororaphis (aureofaciens) strain 30-84: effects on biofilm formation and pathogen inhibition. J. Bacteriol. 190: 2759-2766.

21. Ohkura M, Abawi GS, Smart CD, Hodge KT. 2009. Diversity and aggressiveness of Rhizoctonia solani and Rhizoctonia-like fungi on vegetables in New York. Plant Dis. 93: 615-624.

22. Ahuja SC, Payak MM. 1986. A rating scale for banded leaf and sheath blight of maize. Indian Phytopath. Indian Phytopathologyrecd 36: 338-340

23. Wheeler BEJ. 1969. An Introduction to Plant Diseases. The English language Book Socity And Wiley and Sons Ltd, London.

24. Tamura K, Stecher G, Peterson D, Filipski A, Kumar S. 2013. MEGA6: molecular evolutionary genetics analysis version 6.0. Mol. Biol. Evol. 30: 2725-2729.

25. Culbertson JE, Toney MD. 2013. Expression and characterization of PhzE from P. aeruginosa PAO1: aminodeoxyisochorismate synthase involved in pyocyanin and phenazine-1-carboxylate production. Biochim. Biophys. Acta Proteins Proteomics 1834: 240-246.
26. Schneemann I, Wiese J, Kunz AL, Imhoff JF. 2011. Genetic approach for the fast discovery of phenazine producing bacteria. Mar. Drugs 9: 772-789.

27. SAS Institute Inc. 2008. SAS/STAT 9.2 User's Guide. Cary, NC: Institute Inc.

28. Andreani NA, Martino ME, Fasolato L, Carraro L, Montemurro F, Mioni R, et al. 2015. Tracking the blue: a MLST approach to characterise the Pseudomonas fluorescens group. Food Microbiol. 45: 148-158.

29. Devi TV, Vizhi RM, Sakthivel N, Gnanamanickam SS. 1989. Biological control of sheath-blight of rice in India with antagonistic bacteria. Plant Soil 119: 325-330.

30. Nejad MS, Bonjar GHS, Khatami M, Amini A, Aghighi S. 2016. In vitro and in vivo antifungal properties of silver nanoparticles against Rhizoctonia solani, a common agent of rice sheath blight disease. IET. Nanobiotechnol. 11: 236-240.

31. Thrane C, Nielsen MN, Sørensen J, Olsson S. 2001. Pseudomonas fluorescens DR54 reduces sclerotia formation, biomass development, and disease incidence of Rhizoctonia solani causing damping-off in sugar beet. Microb. Ecol. 42: 438-445.

32. Tariq M, Yasmin S, Hafeez FY. 2010. Biological control of potato black scurf by rhizosphere associated bacteria. Braz. J. Microbiol. 41: 439-451.

33. Hu QP, Xu JG, Song P, Song JN, Chen WL. 2008. Isolation and identification of a potential biocontrol agent Bacillus subtilis QM3 from Qinghai yak dung in China. World J. Microbiol. Biotechnol. 24: 2451-2458.

34. Kai M, Haustein M, Molina F, Petri A, Scholz B, Piechulla B. 2009. Bacterial volatiles and their action potential. Appl. Microbial. Biotechnol. 81: 1001-1012.

35. Wang JH, Zhang JB, Li HP, Gong AD, Xue S, Agboola RS, et al. 2014. Molecular identification, mycotoxin production and comparative pathogenicity of Fusarium temperatum isolated from maize in China. J. Phytopathol. 162: 147-157.

36. Varela CP, Casal OA, Padin MC, Martinez VF, Oses MS, Scauflaire J, et al. 2013. First report of Fusarium temperatum causing seedling blight and stalk rot on maize in Spain. Plant Dis. 97: 1252-1253.

37. Park HK, Kim BS, Lee WS. 1990. Inheritance of resistance to anthracnose (Colletotrichum spp.) in pepper (Capsicum annuum L.). II. Genetic analysis of resistance to Colletotrichum dematium. J. Kor. Soc. Hort. Sci. 31: 207-212.

38. Du Toit LJ, Derie ML. 2003. Inoculum sources of Stemphylium botryosum and Cladosporium variabile in spinach seed crops. Phytopathology 93: S22.

39. Suárez-Estrella F, Vargas-Garcia C, Lopez MJ, Capel C, Moreno J. 2007. Antagonistic activity of bacteria and fungi from horticultural compost against Fusarium oxysporum f. sp. melonis. Crop Prot. 26: 46-53.

40. Huang CJ, Tsay JF, Chang SY, Yang HP, Wu WS, Chen CY. 2012. Dimethyl disulfide is an induced systemic resistance elicitor produced by Bacillus cereus C1L. Pest Manag. Sci. 68: 
1306-1310

41. Whistler CA, Pierson III LS. 2003. Repression of phenazine antibiotic production in Pseudomonas aureofaciens strain 30-84 by RpeA. J. Bacteriol. 185: 3718-3725.

42. Haas D, Défago G. 2005. Biological control of soil-borne pathogens by fluorescent pseudomonads. Nat. Rev. Microbiol. 3: 307-319.

43. Mavrodi DV, Blankenfeldt W, Thomashow LS. 2006. Phenazine compounds in fluorescent Pseudomonas spp. biosynthesis and regulation. Annu. Rev. Phytopathol. 44: 417-445.

44. He L, Xu YQ, Zhang XH. 2008. Medium factor optimization and fermentation kinetics for phenazine-1-carboxylic acid production by Pseudomonas sp. M18G. Biotechnol. Bioeng. 100: 250-259.

45. Chin-A-Woeng TF, Thomas-Oates JE, Lugtenberg BJ, Bloemberg GV. 2001. Introduction of the phzH gene of Pseudomonas chlororaphis PCL1391 extends the range of biocontrol ability of phenazine-1-carboxylic acid-producing Pseudomonas spp. strains. Mol. Plant Microbe Interact. 14: 1006-1015.

46. Yuan M, Yu Y, Li HR, Dong N, Zhang XH. 2014. Phylogenetic diversity and biological activity of actinobacteria isolated from the Chukchi Shelf marine sediments in the Arctic Ocean. Mar. Drug. 12: 1281-1297.

47. Passari AK, Chandra P, Leo VV, Mishra VK, Kumar B, Singh BP. 2017. Production of potent antimicrobial compounds from Streptomyces cyaneofuscatus associated with fresh water sediment. Front. Microbiol. 8: 68.

48. Cordero P, Príncipe A, Jofré E, Mori G, Fischer S. 2014. Inhibition of the phytopathogenic fungus Fusarium proliferatum by volatile compounds produced by Pseudomonas. Arch. Microbiol. 196: 803-809.

49. Hunziker L, Bönisch D, Groenhagen U, Bailly A, Schulz S, Weisskopf L. 2015. Pseudomonas strains naturally associated with potato plants produce volatiles with high potential for inhibition of Phytophthora infestans. Appl. Environ. Microbiol. 81: 821-830.

50. Velivelli SL, Kromann P, Lojan P, Rojas M, Franco J, Suarez JP, et al. 2015. Identification of mVOCs from Andean rhizobacteria and field evaluation of bacterial and mycorrhizal inoculants on growth of potato in its center of origin. Microb. Ecol. 69: 652-667.

51. Lin Y, Liu Q, Cheng L, Lei Y, Zhang A. 2014. Synthesis and antimicrobial activities of polysiloxane-containing quaternary ammonium salts on bacteria and phytopathogenic fungi. React. Funct. Polym. 85: 36-44.

52. Schöller C, Molin S, Wilkins K. 1997. Volatile metabolites from some gram-negative bacteria. Chemosphere 35: 1487-1495.

53. Holopainen JK. 2004. Multiple functions of inducible plant volatiles. Trends Plant Sci. 9: 529-533.

54. Meldau DG, Meldau S, Hoang LH, Underberg S, Wünsche H, Baldwin IT. 2013. Dimethyl disulfide produced by the naturally associated bacterium Bacillus sp B55 promotes
Nicotiana attenuata growth by enhancing sulfur nutrition. Plant Cell 25: 2731-2747.

55. Hernández-León R, Rojas-Solís D, Contreras-Pérez M, del Carmen Orozco-Mosqueda M, Macías-Rodríguez LI, Reyesde la Cruz H, et al. 2015. Characterization of the antifungal and plant growth-promoting effects of diffusible and volatile organic compounds produced by Pseudomonas fluorescens strains. Biol. Control 81: 83-92.

56. Jiao Z, Wu N, Hale L, Wu W, Wu D, Guo Y. 2013. Characterisation of Pseudomonas chlororaphis subsp. aurantiaca strain Pa40 with the ability to control wheat sharp eyespot disease Ann. Appl. Biol. 163: 444-453.

57. Shahid I, Rizwan M, Baig DN, Saleem RS, Malik KA, Mehnaz S. 2017. Secondary metabolites production and plant growth promotion by Pseudomonas chlororaphis and P. aurantiaca strains isolated from cactus, cotton, and para grass. J. Microbiol. Biotechnol. 27: 480-491.

58. Alemu F, Alemu T. 2015. Pseudomonas fluorescens isolates used as a plant growth promoter of Faba Bean (Vicia faba) in vitro as well as in vivo study in Ethiopia. Am. J. Life Sc. 3: $100-108$.

59. Jha CK, Patel B, Saraf M. 2012. Stimulation of the growth of Jatropha curcas by the plant growth promoting bacterium Enterobacter cancerogenus MSA2. World J. Microbiol. Biotechnol. 28: 891-899.

60. Bhattacharyya PN, Jha DK. 2012. Plant growth-promoting rhizobacteria (PGPR): emergence in agriculture. World J. Microbiol. Biotechnol. 28: 1327-1350.

61. Hrynkiewicz K, Baum C, Leinweber P. 2010. Density, metabolic activity, and identity of cultivable rhizosphere bacteria on Salix viminalis in disturbed arable and landfill soils. J. Plant Nutr. Soil Sci. 173: 747-756.

62. Sivakumar G, Sharma RC, Rai SN. 2000. Biocontrol of banded leaf and sheath blight of maize by peat based Pseudomonas fluorescens formulation. Indian Phytopathol. 53: 190-192.

63. Kozdrój J, Trevors JT, Van Elsas JD. 2004. Influence of introduced potential biocontrol agents on maize seedling growth and bacterial community structure in the rhizosphere. Soil Biol. Biochem. 36: 1775-1784.

64. Sandhya VS, Ali SZ, Grover M, Reddy G, Venkateswarlu B. 2010. Effect of plant growth promoting Pseudomonas spp. on compatible solutes, antioxidant status and plant growth of maize under drought stress. Plant Growth Regul. 62: 21-30.

65. Glick BR, Cheng Z, Czarny J, Duan J. 2007. Promotion of plant growth by ACC deaminase-producing soil bacteria. Eur. J. Plant Pathol. 119: 329-339.

66. Dimkpa CO, Merten D, Svatoš A, Büchel G, Kothe E. 2009. Siderophores mediate reduced and increased uptake of cadmium by Streptomyces tendae F4 and sunflower (Helianthus annuus), respectively. J. Appl. Microbiol. 107: 1687-1696.

67. Anees M, Edel-Hermann V, Steinberg C. 2010. Build up of patches caused by Rhizoctonia solani. Soil Biol. Biochem. 42: 1661-1672. 